\title{
Influence of Unconscious Emotional Control Goals Priming on Anticipatory Anxiety and Physiological Activity
}

\author{
Lulu Hou',2, Xiufeng Yan³, Qi Jiang1,2, Huanzhen Wang1,2, Changran Li, ${ }^{1,2}$ \\ ${ }^{1}$ Institution of Mental Health Education, Southwest University, Chongqing, China \\ ${ }^{2}$ Faculty of Psychology, Southwest University, Chongqing, China \\ ${ }^{3}$ Organization Department of CPC DaTong Committee, Datong, China \\ Email: jiangqi@swu.edu.cn
}

How to cite this paper: Hou, L.L., Yan, X.F., Jiang, Q., Wang, H.Z. and Li, C.R. (2016) Influence of Unconscious Emotional Control Goals Priming on Anticipatory Anxiety and Physiological Activity. Health, 8, 1589-1602.

http://dx.doi.org/10.4236/health.2016.814156

Received: October 19, 2016

Accepted: November 21, 2016

Published: November 24, 2016

Copyright $\odot 2016$ by authors and Scientific Research Publishing Inc. This work is licensed under the Creative Commons Attribution International License (CC BY 4.0).

http://creativecommons.org/licenses/by/4.0/

\begin{abstract}
Individuals frequently generate emotion during the anticipation process and the anticipatory emotion has an important adaptive significance, especially the negative anticipative emotion. Many researches used conscious emotion regulation strategy and successfully reduced negative anticipatory emotion. However, it is costly for our limited cognition. In the present study, we used sentence unscrambling tasks to prime unconscious emotion control goal and investigated its effect on anticipatory anxiety, including experience and physiological activity. The results showed that 1) relative to anticipating neutral images, participations' anxiety experience and skin conductance level were higher when anticipating negative and unknown images; 2) participants who had a unconscious emotion control goal primed achieved the same decrease in skin conductance as those explicitly instructed to reappraise, compared to a control group; 3) heart rate was not affected by experiment condition and anticipation type. Together, these findings suggest that unconscious emotion regulation may provide an effective mean of regulating negative anticipatory emotion.
\end{abstract}

\section{Keywords}

Anticipatory Anxiety, Physiological Activity, Unconscious Emotional Control Goals Priming

\section{Introduction}

There is no terror in a bang, only in the anticipation of it-Alfred Hitchcock

Our daily life is always filled with a lot of emotionally stimulating information, such 
as yesterday's birthday, present homework, and incoming exam; all have the potential to influence people's emotional lives. Anticipatory emotion has been defined as current emotion experience due to the prospect of a desirable or undesirable future event [1]. Researches indicated that anticipatory emotion had influences on our cognitive processes, decision-making, and physical-mental health [2] [3] [4]. Insufficient or excessive anticipatory emotion would lead to mental illness; for instance, there were characteristics of excessive negative anticipatory emotion or lack of positive anticipatory emotion among patients with anxiety disorder, depression disorder, or psychosis [5] [6] [7] [8]. Therefore, people often attempt to regulate distressing anticipatory emotional states, such as anticipatory anxiety. However, most researchers focused on the cognitive processes of anticipation while there was little research paid attention to the anticipatory emotion and its regulation [9] [10] [11].

According to Gross and Thompson's theory [12], emotion regulation strategies include conscious emotion regulation (e.g. cognitive reappraisal, suppression) and unconscious emotion regulation. There were many researches that indicated conscious emotional regulation was effective on reducing negative anticipatory emotion, including subjective experience, physiological activity and brain activity [13] [14] [15]. However, these conscious emotion regulations have significant costs for the individual and have difficulties in many situations, such as anxiety in the stress environment [16]. Ideally, there would be a way for individuals to regulate anticipatory emotion whenever they need and "cost-free". However, is that possible?

Unconscious emotion regulation has been defined as the unintentional, automatic, and relatively effortless control of one's exposure to, processing of, and response to emotionally evocative events [17]. On the one hand, in the past researches, habitual usage of certain emotion regulation was proved effective on reducing negative anticipatory emotion, such as anxiety. For example, Carlson and his colleague found that individuals who score high in dispositional reappraisal could reduce the activity of anterior insula, which could indicate the anxiety even without the instruction of cognitive reappraisal, during aversive anticipation [18]. Abler et al. chose 30 individuals who did not show symptoms of clinical depression and scored either relatively high or low suppression on Emotion Regulation Questionnaire, as participants to anticipate images selected from International Affective Picture System [19]. The results showed that individuals with high suppression scores decreased activation of the orbital medial prefrontal cortex (OMFC), which could indicate a lack of antecedent emotion regulation, when expecting negative pictures. With comparing the anticipatory emotion of individuals who score high or low in a certain emotion regulation strategy during the anticipation tasks, these studies provide a possibility to develop unconscious regulation of anticipatory emotion. However, there was no causal relationship between them or direct proof which can prove unconscious regulation could successfully reduce anticipatory emotion. Furthermore, if it is effective for the individuals of habitual usage cognitive reappraisal to regulate anticipatory emotion, what about those who score low in dispositional reappraisal? 
On the other hand, some researches discussed this question based on the mechanism of unconscious emotion regulation-unconscious goal pursuit [16] [20] [21]. The goal pursuit theory proposed that goal could be activated by corresponding clues, such as semantic priming, instrument priming and interpersonal priming [22] [23] and further directed to individuals' behavior [24], which has the same effect with conscious goal pursuit [25]. Mauss et al. firstly used sentence unscrambling tasks effective priming emotional expression and emotional regulation, then found that relative to priming emotion expression, priming emotion control could reduce negative emotion experience without maladaptive cardiovascular responding [21]. Tamir, Ford, and Ryan found that unconscious collaboration goal priming could reduce individuals' anger experience [26], which was also effective for negative emotion pictures [27] [28]. Since it is feasible for the regulation for negative emotion, is it also effective for anticipatory emotion?

Above all, the most researches focused on the cognitive process of anticipation and neglected anticipatory emotion with it. It was the first aim of this present study. Furthermore, to date, there was few researches had direct investigated the unconscious regulation of anticipatory emotion although habitual cognitive reappraisal was effective on reducing anticipatory emotion. Therefore, we studied unconscious emotion regulation of anticipatory emotion based on unconscious goal pursuit theory and it was the primary aim of this research. On the end, many researchers studied the brain activity of anticipatory emotion, while physiological activity was also important for the discussion of the regulation of anticipatory emotion. So, we used heart rate and skin conductance level as the physiological activity indicators of emotion, which were common and effective to reflect the change of emotion [29] [30] [31] [32].

\section{Method}

\subsection{Participants}

Participants included 85 undergraduate students (44 females) at Southwest University. All participants were free of neurological and psychiatric disorders (self-report) and all were right-handed. All participants completed the whole experiment procedure. In order to study the effects of instruction manipulation on dependent variables, eleven participants were excluded in the final analysis, nine due to not execute instruction at all and, two, because they were suspicious about the "imagery ability test". A total of 74 participants (mean age $=21.48$ years) were selected and randomly assigned to control condition $(n=26)$, conscious emotion regulation condition $(n=25)$ or unconscious emotion control goal condition $(n=23)$. All participants gave their written informed consent after receiving a detailed explanation of the experiments. After the experiment, they were paid 10 Yuan for their participation. The study protocol was approved by the relevant ethics institution.

\subsection{Self-Report Measures}

Self-rating Depression Scale (SDS) was used to assess depression symptoms using a 
scale covering affective, psychological and somatic symptoms associated with depression on a 4-point Likert scale ranging from 1 (a little of the time) to 4 (most of the time) [33]. The SDS is a 20-item scale and has high internal consistency $(\alpha=0.87)$ [34].

Trait Anxiety Inventory (TAI) was used to assess one's tendency to respond fearfully to anxiety-related symptoms on a 4-point Likert scale ranging from 1 (almost never) to 4 (almost always) [35]. The TAI is a 20-item scale and has high internal consistency ( $\alpha$ $=0.90)[36]$.

\subsection{Emotional Images}

The 24 images of this research were all selected from the pre-study. In the pre-study, 17 participants were asked to rate the arousal and valence of 40 images from the International Affective Picture System (IAPS) [37] by Self-Assessment Manikin Scale (SAM) [38]. On the end, we obtained 12 neutral images (arousal: $M=4.09, S D=0.50$; valence: $M=4.88, S D=0.22$ ) and 12 negative images (arousal: $M=6.31, S D=0.38$; valence: $M$ $=2.21, S D=0.28$ ).

\subsection{Priming Stimuli}

To manipulate unconscious emotion regulation, we adapted the Sentence Unscrambling Task [27] [28], in which participants have to construct grammatical four-word sentences from five-word jumbles. These sentences included 8 emotion control conditions and 15 neutral conditions.

\subsection{Physiological Activity}

Two measures of Physiological activity included heart rate and skin conductance level were sampled at $32 \mathrm{~Hz}$ using laboratory software.

Heart Rate (HR; beats/Min) was calculated from RR intervals. During each heartbeat, when blood flow through blood vessels, the maximum of the blood flow was called peak. HR was calculated from the interval of the twice peak. Sensor was placed in the fingers of the left hand.

Skin Conductance Level (SCL; V) was measured through the skin conductance sensors which placed in the middle and ring finger of the left hand.

\subsection{Procedure}

Upon arrival to the laboratory, written consent was obtained from each participant. After signing the consent form, participants were then randomly assigned to one of the three conditions. Participants of the conscious emotion regulation condition were introduced the knowledge and strategy of cognitive reappraisal by a research assistant, who attached a series of physiological sensors to them while the participants of the control condition and unconscious emotion control goal condition were only attached the physiological sensors.

While the participant was waiting, a blank screen which lasted three-minute was shown to establish baseline physiological activation. Once the video was over, the re- 
search assistant informed participants that they'd be participating in an "imagery ability test". Between the practice stage and the formal experiment stage, there was a linguistic exam. At this point, practice stage which included 2 trials for each condition was beginning. During the practice stage, a fixation presented first then there was a prompt (“ $\downarrow$ ”, “-”, or “?") on the screen. Participants were asked to anticipate the content of the incoming images according to the prompt and pay attention to their current emotion, and the prompt of “ $\downarrow$ ”, “-”, and "?" represent negative anticipation, neutral anticipation and unknown anticipation, respectively. In the unknown anticipation, half of the target images are negative, and the others are neutral. Next, participants reported on their anxiety experience using a Likert scale ranging from 1 (none at all) to 6 (extremely). After presenting the target images for 4 seconds, there were 17 seconds to return to neutral mood before next trial (note: In the pre-study, we also investigated the recovery time after the presentation of images. The results indicated that the three trend lines of SCL of negative, positive and neutral anticipation conditions intersected and began to go flat around 17 seconds, while the trend lines of HR were always in fluctuation. Therefore, we set the duration of recovery as 17 seconds). Figure 1 shows the time course for a single trial. At this time, participants were asked to complete sentence unscrambling task. In this stage, participants of unconscious emotion control goal condition completed 8 emotion regulation sentences and 7 neutral sentences while participants of the control condition and conscious emotion regulation condition completed 15 neutral sentences.

After completed the sentence unscrambling task, the formal experiment stage began. Formal experiment stage was presented with 10 trials per condition in a pseudo random sequence. The procedure of formal stage was the same as the procedure of practice stage. Figure 1 showed the time course for a single trial of the practice stage and formal experiment stage.

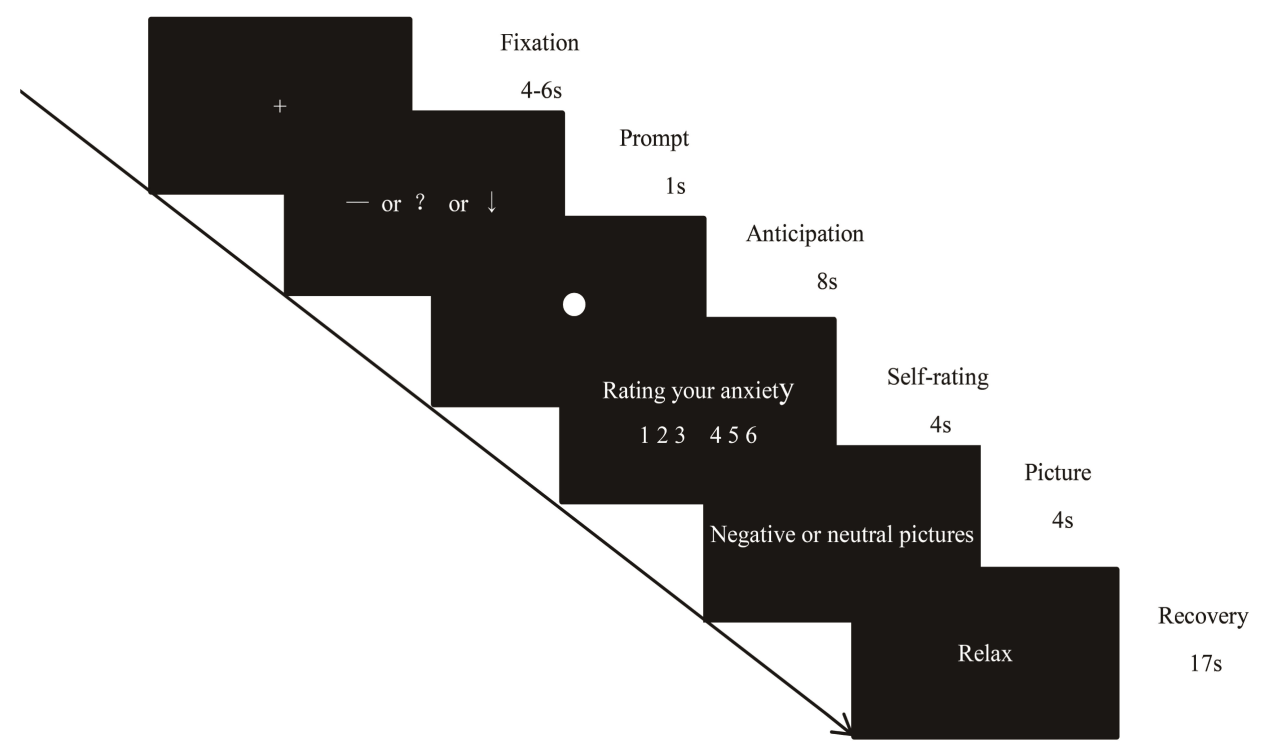

Figure 1. Example of time course for one trial. 
Then, sensors were removed and participants completed the Self-rating Depression Scale (SDS) and Trait Anxiety Inventory (TAI). On the end, participants were asked to rate 1 (not at all) to 3 (absolutely) to assess the extent to execute instruction and reported whether they were aware of the true nature of the "imagery ability test".

\section{Results}

The following data analytic strategy was used. (a) To ascertain that randomization was successful, one-way ANOVAs comparing the three experiment conditions for each DV (Dependent Variable) were performed. (b) To assess the effectiveness of the emotion control goal, we conducted ANCOVAs for process value of physiological activity, with experiment condition (unconscious emotion control goal condition, conscious emotion regulation condition, and control condition) as a group factor and anticipation type (negative anticipation, neutral anticipation, and unknown anticipation) as a repeated-measures factor and baseline responding as the covariate. (c) To assess the changing extent of physiological activity, we conducted omnibus ANOVAs for the change rate of physiological activity, with experiment condition(unconscious emotion control goal condition, conscious emotion regulation condition, control condition) as a group factor, and anticipation type (negative anticipation, neutral anticipation, unknown anticipation) as a repeated-measures factor. The following sections show (a) randomization checks, (b) results of ANCOVAs, (c) results of omnibus ANOVAs.

\subsection{Randomization Checks}

To ascertain that randomization was successful, one-way ANOVAs were used to compare the three conditions. As Table 1 indicated, none of the effects of condition were significant (all $p s>0.3$ ) (see Table 1), indicating that there were no group differences in emotion experience or physiological responding before or during the experiment and in the daily life.

\subsection{Effects of Emotion Regulation Goal Priming}

To examine whether emotion regulation goal priming led to differences in emotional

Table 1. Descriptive statistics for different conditions on physiological response baseline and other variables $(\mathrm{M} \pm \mathrm{SD})$.

\begin{tabular}{cccc}
\hline & $\begin{array}{c}\text { Unconscious emotion } \\
\text { control goal condition } \\
(n=23)\end{array}$ & $\begin{array}{c}\text { Conscious emotion } \\
\text { regulation condition } \\
(n=25)\end{array}$ & $\begin{array}{c}\text { Control condition } \\
(n=26)\end{array}$ \\
\hline HR baseline & $1.40 \pm 0.88$ & $1.35 \pm 0.81$ & $1.48 \pm 0.85$ \\
SCL baseline & $75.96 \pm 20.96$ & $75.87 \pm 35.17$ & $66.64 \pm 17.74$ \\
Sentence unscrambling task RT & $241.74 \pm 41.32$ & $225.53 \pm 35.94$ & $234.34 \pm 44.79$ \\
SDS score & $35.65 \pm 8.60$ & $33.28 \pm 6.32$ & $35.96 \pm 9.22$ \\
TAI score & $40.00 \pm 6.36$ & $38.16 \pm 84.95$ & $40.27 \pm 7.42$ \\
\hline
\end{tabular}

Note. $\mathrm{M}=$ Mean; $\mathrm{SD}$ = Standard Deviation; $\mathrm{HR}=$ Heart Rate; $\mathrm{SCL}=$ Skin Conductance Level; RT = Reaction Time; SDS $=$ Self-rating Depression Scale; TAI $=$ Trait Anxiety Inventory. 
responding, we conducted ANCOVAs with experiment condition (unconscious emotion control goal condition, conscious emotion regulation condition, and control condition) as the group factor, anticipation type (negative anticipation, neutral anticipation, and unknown anticipation) as a repeated-measures factor and baseline responding as the covariate.

For heart rate, this test revealed a significantly covariate effect, $F(1,70)=13.28, p<$ $0.01, \eta^{2}=0.16$, which indicated that heart rate process value was influenced by the baseline when participants were asked to anticipant different images. However, there was not significantly main effect for experiment condition and anticipation type, as well as the interaction of experiment condition by anticipation type (all $p s>0.30$ ) (see Table 2).

For skin conductance level, this test revealed a significantly covariate effect, $F(1,70)$ $=443.216, p<0.01, \eta^{2}=0.86$, which indicated that skin conductance level process value was influenced by the baseline when participants were asked to anticipant different images.

Furthermore, there was a significantly main effect for experiment condition, $F(2,70)$ $=3.11, p=0.05, \eta^{2}=0.08$, and the post-hoc revealed that the skin conductance level process value of unconscious emotion control goal condition and conscious emotion regulation condition was lower than control condition $(p s<0.01)$ while there was no difference between unconscious emotion control goal condition and conscious emotion regulation condition $(p>0.05)$. There was also a significantly main effect of anticipation type, $F(2,140)=4.29, p=0.03, \eta^{2}=0.06$, and the post-hoc revealed that the skin conductance level process value of anticipation of negative images and unknown images was higher than anticipation of neutral images $(p s<0.05)$ while there was no difference when participants anticipated negative and unknown images $(p>0.05)$. However, there was no significantly interaction effect of experiment condition by anticipation type $(p>0.05)$ (see Table 2$)$.

\subsection{Results of the Omnibus ANOVAs}

To further analyze the change rate of physiological activity, we conducted a 3 (experiment condition $) \times 3$ (anticipation type) repeated measures ANOVA with change rate of

Table 2. Mean physiological activity for different anticipation type $(M \pm S D)$.

\begin{tabular}{lcccc}
\hline & & $\begin{array}{c}\text { Unconscious } \\
\text { emotion control goal } \\
\text { condition }(n=23)\end{array}$ & $\begin{array}{c}\text { Conscious emotion } \\
\text { regulation } \\
\text { condition }(n=25)\end{array}$ & $\begin{array}{c}\text { Control } \\
\text { condition } \\
(n=26)\end{array}$ \\
\hline \multirow{2}{*}{ HR process value } & Negative anticipation & $109.01 \pm 39.32$ & $104.33 \pm 40.72$ & $95.56 \pm 46.65$ \\
& Neutral anticipation & $108.96 \pm 39.33$ & $104.00 \pm 41.04$ & $95.92 \pm 47.07$ \\
& Unknown anticipation & $109.32 \pm 40.19$ & $103.52 \pm 42.23$ & $95.69 \pm 46.01$ \\
\hline & Negative anticipation & $1.48 \pm 0.86$ & $1.50 \pm 0.91$ & $1.81 \pm 1.11$ \\
& Neutral anticipation & $1.43 \pm 0.83$ & $1.44 \pm 0.86$ & $1.73 \pm 1.16$ \\
& Unknown anticipation & $1.46 \pm 0.83$ & $1.50 \pm 0.89$ & $1.83 \pm 1.11$ \\
\hline
\end{tabular}


SCL (change rate of SCL $=$ (process value of SCL-baseline of SCL)/baseline of SCL $\times$ $100 \%$ [39] as the dependent variable. The results showed a significantly main effect for experiment condition, $F(2,71)=3.30, p=0.04, \eta^{2}=0.09$, and the post-hoc revealed that the change rate of SCL of unconscious emotion control goal condition and conscious emotion regulation condition was lower than control condition $(p s<0.01)$ while there was no difference between unconscious emotion control goal condition and conscious emotion regulation condition $(p>0.05)$. There was also a significantly main effect of anticipation type, $F(2,142)=21.59, p<0.01, \eta^{2}=0.23$, and the post-hoc revealed that the change rate of SCL of anticipation of negative images and unknown images was higher than anticipation of neutral images $(p s<0.01)$ while there was no difference when participants anticipated negative and unknown images $(p>0.05)$. However, there was no significantly interaction effect of experiment condition by anticipation type $(p>0.05)$ (see Figure 2(a)).

To analyze participants' anxiety experience, we conducted a 3(experiment condition) $\times 3$ (anticipation type) repeated measures ANOVA with participants' self-rating anxiety as the dependent variable. There was a significantly main effect of anticipant type, $F(2$, $142)=21.13, p<0.001, \eta^{2}=0.23$, and the post-hoc revealed that the anxiety experience of anticipation of negative images and unknown images was higher than anticipation of neutral images $(p s<0.05)$ while there was no difference when participants anticipated

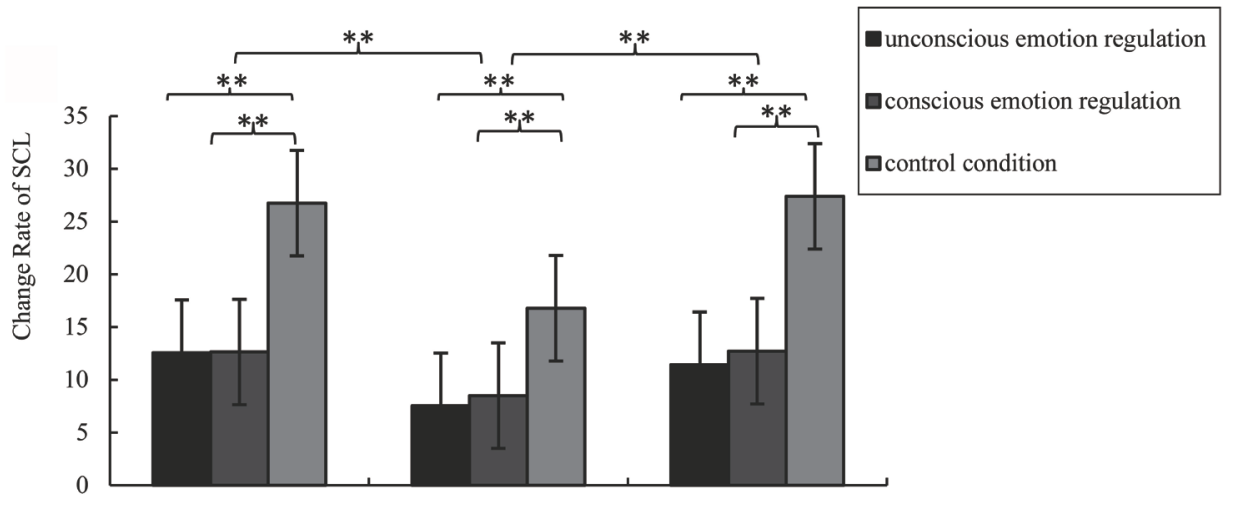

(a)

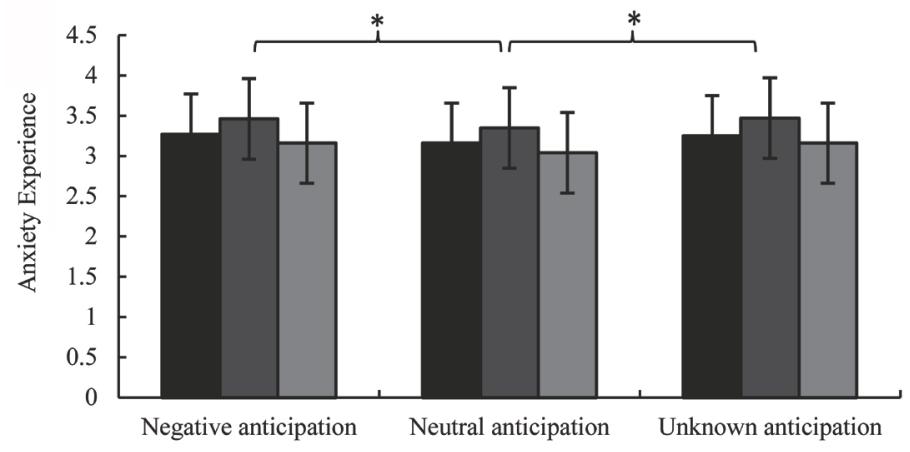

(b)

Figure 2. (a) Change rate of SCL; (b) Anxiety experience for the experiment condition and anticipation type. 
negative and unknown images $(p>0.05)$. However, there was no significantly main effect for experiment condition, as well as the interaction of experiment condition by anticipation type (all $p s>0.50$ ) (see Figure 2(b)).

\section{Discussion}

Individuals often generated a lot of emotion before the things, especially some negative (e.g. anxiety), which have important effect on life. Therefore, it is necessary to regulate the anticipatory emotion. Some researches indicated that instructed cognitive reappraisal was effective on reducing anticipatory emotion [13] [14] [15], but it is costly and difficult [16]. This presents a question, namely whether there is a method to regulate anticipatory emotion cost-free.

Some researches indicated that habitual using emotion strategies could successfully regulate anticipatory emotion [18] [19], which gives us a hint that unconscious emotion regulation may be the key to this question. However, the prior studies of unconscious emotion regulation have relied principally on correlation designs, which make it difficult to assess this hypothesis based on existing research. The present study was designed to fill this gap by providing an experimental manipulation of unconscious emotion regulation by Sentence Unscrambling Tasks and assess the effect of unconscious emotion regulation relative to instructed cognitive reappraisal and control condition.

Results indicated that 1) relative to neutral anticipation, negative and unknown anticipation led to higher anxiety experience and skin conductance level; 2) unconscious emotion control goal priming and conscious emotion regulation led to lower skin conductance level than control condition, while there was no difference between them; 3 ) heart rate is not affected by experiment condition.

\subsection{The Difference between Different Anticipation}

Long-term uncertainty will lead to press and anxiety [40]. The present study support this view due to unknown anticipation led to higher anxiety experience and skin conductance level relative neutral anticipation. However, there was no difference between negative anticipation and unknown anticipation, which is consistent with the prior research [14]. From an evolutionary perspective, we have to prepare ourselves for coping better with a potentially threatening environment. In our present study, anticipating negative and unknown pictures led to higher anxiety experience and skin conductance level relative neutral anticipation means that there was similar anticipatory emotion when anticipating the incoming potential and certain negative events.

\subsection{The Effect of Unconscious Emotion Regulation}

The auto-motive model proposed that frequently used mental representations will, over time, become active upon the mere presence of relevant information in the person's environment and further assumed that, once activated in unconscious manner, the goal representation would then operate in the same way as when it is consciously activated [23]. Empirical researches showed that emotion control goal priming had effect on re- 
ducing physiological activity despite after anger provocation or negative pictures [27] [28] [41]. The present study showed that unconscious emotion control goal priming reduced participants' skin conductance level, consistent with the auto-motive model and prior researches.

However, unconscious emotion control goal priming couldn't reduce anxiety experience, which differs from other studies' findings demonstrating an effect on emotion experience [41]. The discrepancies in findings may arise in part from the fact that the most of the emotion self-rating of the prior researches is the emotion arousal [27] [28] and unconscious emotion goal priming affected only the emotional arousal, but not valence [42] [43].

\subsection{The Difference between Heart Rate and Skin Conductance Level}

Heart rate and skin conductance are two important physiological indexes in the emotion laboratory study. Emotion change leads to sweat increase, and further influence the skin conductance, which indicated the permeability of the skin and sweat gland activity. Therefore, skin conductance is a kind of sensitive and stable emotional physiological index. In the present study, different anticipation led different skin conductance, and relative to neutral anticipation, negative and unknown anticipation led to higher anxiety experience and skin conductance level. This proved that negative and unknown condition led to strong physiological activity, consistent with the self-rating anxiety experience.

However, the finding that heart rate didn't affect by anticipation conditions and emotion regulation condition is consistent with findings of previous researches [44] [45] and differs from other finding's results [31] [46]. The discrepancies in findings may arise in part from the different anxiety inducing paradigm and emotion regulation goal. Above all, skin conductance is a kind of sensitive and stable emotional physiological index while heart rate only reflects emotion activity in some situation.

\subsection{Limitations and Directions}

The present study suggests a number of compelling directions for future research. In the following section, we consider three of the most important limitations and future directions.

First, the present study investigated the effect of unconscious emotion regulation on anticipatory by priming emotion regulation goals but didn't distinguish the specific regulation strategies, which may correlated to individuals' emotional regulation habits in the daily life. In future studies, it is necessary to explore the effect of different emotion regulation strategies (including situation selection, situation modification, attention deployment, cognitive reappraisal and response modulation) on anticipatory emotion in the unconscious level and the relationship between the effect and individuals' life experience. What's more, we only investigated anticipatory anxiety through images priming which indicated there should be other emotion and other methods to be investigated about the unconscious emotion regulation on anticipatory emotion in future studies. 
Second, in the present study, college students as the research samples led to inadequate ecological validity. So it is important to focus on difference samples and pay more attention to special populations, such as anxiety, depression, bipolar disorder patients and other patients with emotion regulation disorder. The use of regulation theory to intervene and treat emotion regulation disorder, perhaps will greatly enrich the research field of emotion regulation strategies, and has high clinical practice significance.

Third, the present study measured the skin conductance level and heart rate. It will be important to assess additional measures (e.g. Skin temperature, pulse and HRV) to reflect the change of whole body or investigate the change participants' emotion expression by using expression encoding technology. Further, some measures (e.g. fMRI) will permit a clearer understanding of the mechanisms underlying the present effects. These are all the future directions.

\section{Conclusion}

The control of negative anticipatory emotion is important in many domains, including cognitive process, decision-making, and physical health. However, conscious negative anticipatory emotion control is difficult to achieve, and seems to be often associated with significant costs for the individuals. The present study provides an effective answer to the question. Firstly, anticipatory anxiety is affected by anticipation types. Related to anticipating neutral images, participations' anxiety experience and skin conductance were higher when anticipating negative and unknown images. And participants who had an emotion-control goal primed and operating unconsciously achieved the same decrease in skin conductance as those explicitly instructed to cognitive reappraise, compared to a control group. Together, unconscious emotion regulation may provide an effective way to regulate negative anticipatory emotion.

\section{References}

[1] Baumgartner, H., Pieters, R. and Bagozzi, R.P. (2008) Future-Oriented Emotions: Conceptualization and Behavioral Effects. European Journal of Social Psychology, 38, 685-696. https:/doi.org/10.1002/ejsp.467

[2] Carrera, P., Caballero, A. and Munoz, D. (2012) Future-Oriented Emotions in the Prediction of Binge-drinking Intention and Expectation: The Role of Anticipated and Anticipatory Emotions. Scandinavian Journal of Psychology, 53, 273-279. https:/doi.org/10.1111/j.1467-9450.2012.00948.x

[3] Poli, S., Sarlo, M., Bortoletto, M., Buodo, G. and Palomba, D. (2007) Stimulus-Preceding Negativity and Heart Rate Changes in Anticipation of Affective Pictures. International Journal of Psychophysiology, 65, 32-39. https:/doi.org/10.1016/j.ijpsycho.2007.02.008

[4] Winterich, K.P. and Haws, K.L. (2011) Helpful Hopefulness: The Effect of Future Positive Emotions on Consumption. Journal of Consumer Research, 38, 505-524. https:/doi.org/10.1086/659873

[5] Chan, R.C.K., Wang, Y., Huang, J., Shi, Y., Wang, Y., Hong, X., et al. (2010) Anticipatory and Consummatory Components of the Experience of Pleasure in Schizophrenia: CrossCultural Validation and Extension. Psychiatry Research, 175, 181-183.

https:/doi.org/10.1016/j.psychres.2009.01.020 
[6] Denny, B.T., Fan, J., Liu, X., Ochsner, K.N., Guerreri, S., Mayson, S.J., et al. (2015) Elevated Amygdala Activity during Reappraisal Anticipation Predicts Anxiety in Avoidant Personality Disorder. Journal of Affective Disorders, 172, 1-7. https:/doi.org/10.1016/j.jad.2014.09.017

[7] Minzenberg, M.J., Fan, J., New, A.S., Tang, C.Y. and Siever, L.J. (2007) Fronto-Limbic Dysfunction in Response to Facial Emotion in Borderline Personality Disorder: An Event-Related fMRI Study. Psychiatry Research: Neuroimaging, 155, 231-243.

https:/doi.org/10.1016/j.pscychresns.2007.03.006

[8] Mote, J., Minzenberg, M.J., Carter, C. and Kring, A.M. (2014) Deficits in Anticipatory But Not Consummatory Pleasure in People with Recent-Onset Schizophrenia Spectrum Disorders. Schizophrenia Research, 159, 76-79. https:/doi.org/10.1016/j.schres.2014.07.048

[9] Denny, B.T., Ochsner, K.N., Weber, J. and Wager, T.D. (2014) Anticipatory Brain Activity Predicts the Success or Failure of Subsequent Emotion Regulation. Social Cognitive and Affective Neuroscience, 9, 403-411. https:/doi.org/10.1093/scan/nss148

[10] Galli, G., Griffiths, V.A. and Otten, L.J. (2012) Emotion Regulation Modulates A-Nticipatory Brain Activity that Predicts Emotional Memory Encoding in Women. Social Cognitive and Affective Neuroscience, 9, 113-117.

[11] Turan, B., Foltz, C., Cavanagh, J.F., Wallace, B.A., Cullen, M., Rosenberg, E.L., et al. (2015) Anticipatory Sensitization to Repeated Stressors: The Role of Initial Cortisol Reactivity and Meditation/Emotion Skills Training. Psychoneuroendocrinology, 52, 229-238. https:/doi.org/10.1016/j.psyneuen.2014.11.014

[12] Gross, J.J. (2007) Emotion Regulation: Conceptual Foundations. In: Gross, J.J., Ed., Handbook of Emotion Regulation, Guilford Press, New York, 3-24.

[13] Herwig, U., Baumgartner, T., Kaffenberger, T., Brühl, A., Kottlow, M., Schreiter-Gasser, U., et al. (2007) Modulation of Anticipatory Emotion and Perception Processing by Cognitive Control. NeuroImage, 37, 652-662. https:/doi.org/10.1016/j.neuroimage.2007.05.023

[14] Herwig, U., Kaffenberger, T., Baumgartner, T. and Jäncke, L. (2007) Neural Correlates of a "Pessimistic" Attitude When Anticipating Events of Unknown Emotional Valence. NeuroImage, 34, 848-858. https:/doi.org/10.1016/j.neuroimage.2006.09.035

[15] König, D., Hold, B., Schramml, J., Pfabigan, D., Blechert, J. and Lamm, C. (2014) Emotion Regulation (ER) during Experimental Pain Stimulation in Migraine Patients and Controls. European Health Psychologist, 16, 514.

[16] Williams, L.E., Bargh, J.A., Nocera, C.C. and Gray, J.R. (2009) The Unconscious Regulation of Emotion: Nonconscious Reappraisal Goals Modulate Emotional Reactivity. Emotion, 9, 847-854https:/doi.org/10.1037/a0017745

[17] Bargh, J.A. and Williams, L.E. (2007) The Nonconscious Regulation of Emotion. In: Gross, J.J., Ed., Handbook of Emotion Regulation, Guilford Press, New York, 429-445.

[18] Carlson, J.M. and Mujica-Parodi, L. (2010) A Disposition to Reappraise Decreases Anterior Insula Reactivity during Anxious Anticipation. Biological Psychology, 85, 383-385. https:/doi.org/10.1016/j.biopsycho.2010.08.010

[19] Abler, B., Hofer, C., Walter, H., Erk, S., Hoffmann, H., Traue, H.C., et al. (2010) Habitual Emotion Regulation Strategies and Depressive Symptoms in Healthy Subjects Predict fMRI Brain Activation Patterns Related to Major Depression. Psychiatry Research: Neuroimaging, 183, 105-113. https:/doi.org/10.1016/j.pscychresns.2010.05.010

[20] Gallo, I.S., Keil, A., McCulloch, K.C., Rockstroh, B. and Gollwitzer, P.M. (2009) Strategic Automation of Emotion Regulation. Journal of Personality and Social Psychology, 96, 1131. https:/doi.org/10.1037/a0013460 
[21] Mauss, I.B., Cook, C.L. and Gross, J.J. (2007) Automatic Emotion Regulation during Anger Provocation. Journal of Experimental Social Psychology, 43, 698-711. https:/doi.org/10.1016/j.jesp.2006.07.003

[22] Shah, J.Y. (2005) The Automatic Pursuit and Management of Goals. Current Directions in Psychological Science, 14, 10-13. https:/doi.org/10.1111/j.0963-7214.2005.00325.x

[23] Gollwitzer, P.M. and Bargh, J.A. (2005) Automaticity in Goal Pursuit. In: Elliot, A.J. and Dweck, C.S., Eds., Handbook of Competence and Motivation, Guilford Press, New York, 624-646.

[24] Hassin, R.R., Bargh, J.A. and Zimerman, S. (2009) Automatic and Flexible: The Case of Non-Conscious Goal Ppursuit. Social Cognition, 27, 20-36. https:/doi.org/10.1521/soco.2009.27.1.20

[25] Bargh, J.A. and Morsella, E. (2010) Unconscious Behavioral Guidance Systems. In: Agnew, C., Carlston, D., Graziano, W. and Kelly, J., Eds., Then a Miracle Occurs. Focusing on Behavior in Social Psychological Theory and Research, Oxford University Press, New York, 89-118.

[26] Tamir, M., Ford, B.Q. and Ryan, E. (2013) Nonconscious Goals Can Shape What People Want to Feel. Journal of Experimental Social Psychology, 49, 292-297. https:/doi.org/10.1016/j.jesp.2012.11.009

[27] Ma, W.N. (2010) Mechanism and Application on Implicit Attitude to Emotion Regulation Modulating Emotional Reactivity. East China Normal University, Shanghai. (In Chinese)

[28] Yao, Y.J. (2011) The Unconscious Emotion Regulation: Cognitive Reappraisal and Expressive Suppression Regulate Emotional Reaponse. Hangzhou Normal Univeraity, Hangzhou. (In Chinese)

[29] Drabant, E.M., Kuo, J.R., Ramel, W., Blechert, J., Edge, M.D., Cooper, J.R., et al. (2011) Experiential, Autonomic, and Neural Responses during Threat Anticipation Vary as a Function of Threat Intensity and Neuroticism. NeuroImage, 55, 401-410. https:/doi.org/10.1016/j.neuroimage.2010.11.040

[30] Gramer, M. and Saria, K. (2007) Effects of Social Anxiety and Evaluative Threat on Cardiovascular Responses to Active Performance Situations. Biological Psychology, 74, 67-74. https:/doi.org/10.1016/j.biopsycho.2006.07.004

[31] Williams, B., Craig, I., Telang, F., Biegon, A., Wang, G., Fowler, J., et al. (2009) Neural Mechanisms of Anger Regulation as a Function of Genetic Risk for Violence. Emotion, 9, 385396. https:/doi.org/10.1037/a0015904

[32] Wong, Q.J. and Moulds, M.L. (2011) Impact of Anticipatory Processing versus Distraction on Multiple Indices of Anxiety in Socially Anxious Individuals. Behaviour Research and therapy, 49, 700-706. https:/doi.org/10.1016/j.brat.2011.07.007

[33] Zung, W.W., Richards, C.B. and Short, M.J. (1965) Self-Rating Depression Scale in an Outpatient Clinic: Further Validation of the SDS. Archives of General Psychiatry, 13, 508-515. https:/doi.org/10.1001/archpsyc.1965.01730060026004

[34] Yesavage, J.A., Brink, T., Rose, T.L., Lum, O., Huang, V., Adey, M., et al. (1983) Development and Validation of a Geriatric Depression Screening Scale: A Preliminary Report. Journal of Psychiatric Research, 17, 37-49. https:/doi.org/10.1016/0022-3956(82)90033-4

[35] Spielberger, C.D. and Sydeman, S.J. (1994) State-Trait Anxiety Inventory and State-Trait Anger Expression Inventory. In: Maruish, M.E., Ed., The Use of Psychological Testing for Treatment Planning and Outcome Assessment, Lawrence Erlbaum, Hillsdale, 292-321.

[36] Kabacoff, R.I., Segal, D.L., Hersen, M. and Van Hasselt, V.B. (1997) Psychometric Properties and Diagnostic Utility of the Beck Anxiety Inventory and the State-Trait Anxiety In- 
ventory with Older Adult Psychiatric Outpatients. Journal of Anxiety Disorders, 11, 33-47. https:/doi.org/10.1016/S0887-6185(96)00033-3

[37] Lang, P.J., Bradley, M.M. and Cuthbert, B.N. (1997) International Affective Picture System (IAPS): Technical Manual and Affective Ratings. NIMH Center for the Study of Emotion and Attention, 39-58.

[38] Lang, P. (1980) Self-Assessment Manikin. The Center for Research in Psychophysiology, University of Florida, Gainesville.

[39] Wu, M.Y., Zhou, R.L., Huang, Y.M., Wang, Q.G., Zhao, Y. and Liu, Y.F. (2014) Effects of Menstrual Cycle and Neuroticism on Emotional Responses of Healthy Women. Acta Psychologica Sinica, 46, 58-68.

[40] Smith, C.A. and Lazarus, R.S. (1990) Emotion and Adaptation. In: Pervin, L.A., Ed., Handbook of Personality. Theory and Research, Guilford Press, New York, 609-637.

[41] Mauss, I.B., Cook, C.L., Cheng, J.Y. and Gross, J.J. (2007) Individual Differences in Cognitive Reappraisal: Experiential and Physiological Responses to an Anger Provocation. International Journal of Psychophysiology, 66, 116-124. https:/doi.org/10.1016/j.ijpsycho.2007.03.017

[42] Dooren, M.V., Vries, J.J.G.D. and Janssen, J.H. (2012) Emotional Sweating across the Body: Comparing 16 Different Skin Conductance Measurement Locations. Physiology and Behavior, 106, 298-304. https:/doi.org/10.1016/j.physbeh.2012.01.020

[43] Lang, P.J. and Bradley, M.M. (2010) Emotion and the Motivational Brain. Biological Psychology, 84, 437-450. https:/doi.org/10.1016/j.biopsycho.2009.10.007

[44] Butler, E.A., Wilhelm, F.H. and Gross, J.J. (2006) Respiratory Sinus Arrhythmia, Emotion, and Emotion Regulation during Social Interaction. Psychophysiology, 43, 612-622. https:/doi.org/10.1111/j.1469-8986.2006.00467.x

[45] Urry, H.L. (2009) Using Reappraisal to Regulate Unpleasant Emotional Episodes: Goals and Timing Matter. Emotion, 9, 782-797. https:/doi.org/10.1037/a0017109

[46] Pollatos, O., Herbert, B.M., Matthias, E. and Schandry, R. (2007) Heart Rate Response after Emotional Picture Presentation Is Modulated by Interoceptive Awareness. International Journal of Psychophysiology, 63, 117-124. https:/doi.org/10.1016/j.ijpsycho.2006.09.003 
Submit or recommend next manuscript to SCIRP and we will provide best service for you:

Accepting pre-submission inquiries through Email, Facebook, LinkedIn, Twitter, etc.

A wide selection of journals (inclusive of 9 subjects, more than 200 journals)

Providing 24-hour high-quality service

User-friendly online submission system

Fair and swift peer-review system

Efficient typesetting and proofreading procedure

Display of the result of downloads and visits, as well as the number of cited articles

Maximum dissemination of your research work

Submit your manuscript at: http://papersubmission.scirp.org/

Or contact health@scirp.org 